\title{
Future Raw Material Supply: Opportunities and Limits of Aluminium Recycling in Austria
}

\author{
Hanno Buchner ${ }^{1} \cdot$ David Laner $^{1} \cdot$ Helmut Rechberger $^{2} \cdot$ Johann Fellner $^{1}$
}

Published online: 25 September 2015

(C) The Minerals, Metals \& Materials Society (TMS) 2015

\begin{abstract}
In order to promote sustainable production by using secondary raw material from existing material stocks, complementary to primary raw material, information about the future availability of secondary resources constitutes a prerequisite. In this study, a dynamic material flow model of historic aluminium (Al) flows in Austria is combined with forecasts on future $\mathrm{Al}$ consumption to estimate the development of old scrap generation and in-use stocks until 2050. In-use stocks are estimated to increase by $60 \%$ to $515 \mathrm{~kg} / \mathrm{cap}$. by 2050 assuming a scenario of moderate economic growth. Old scrap generation in 2050 would thereby more than double (up to $30 \mathrm{~kg} / \mathrm{cap}$.) in comparison to the 2010 amounts. Despite this substantial increase in old scrap generation, industrial self-supply from old scrap will probably not exceed $20 \%$, and final consumption selfsupply of Al will not exceed $40 \%$ given present conditions. Opportunities and limits of increasing self-supply through higher collection rates and lower scrap export levels are investigated in this study as the European Raw Material Initiative considers enhanced recycling to be a key measure to ensure future resource supply. Based on these
\end{abstract}

The contributing editor for this article was S. Kitamura.

Electronic supplementary material The online version of this article (doi:10.1007/s40831-015-0027-3) contains supplementary material, which is available to authorized users.

Hanno Buchner

hanno.buchner@tuwien.ac.at

1 Christian Doppler Laboratory for Anthropogenic Resources, Vienna University of Technology, Karlsplatz 13/226.2, 1040 Vienna, Austria

2 Institute for Water Quality, Resource and Waste Management, Vienna University of Technology, Karlsplatz 13, 1040 Vienna, Austria analyses, a self-sustaining Al supply from post-consumer $\mathrm{Al}$ is not expected if current trends of $\mathrm{Al}$ usage continue. Therefore, comprehensive resource policy should be based on a profound understanding of the availability of primary and secondary resources potentials and their dynamics.

Keywords Future aluminium scrap · Recycling · Secondary raw material supply $\cdot$ Dynamic material flow modelling

\section{Introduction}

The latest economic crisis underlined that industry is an important pillar of the European economy. In order to strengthen the European economy, the European Commission aims to raise the share of manufacturing back to $20 \%$ of GDP by 2020 [1]. The supply of industry with raw materials has been identified as one of the major weaknesses hampering the growth of industry [2]. Therefore, several raw material initiatives $[3,4]$ have been launched in order to secure raw material availability. The EU strategies focus on three core aspects: (1) access to raw materials on global markets, (2) sustainable extraction of primary raw materials in the EU and (3) increasing recycling and resource efficiency as well as substitution of critical materials in order to ease the dependence on primary raw material imports [5]. Even though aluminium (Al) is not on the list of materials facing a critical shortage, the material amount provided from mining production within the EU is below $10 \%$ of global supply [6]. Due to high energy costs and strict environmental regulations, Europe is facing a decreasing trend in primary production, reaching a level below two million tonnes in 2013 [7], corresponding to $14 \%$ of total European Al supply. Despite economic 
disruptions between 2008 and 2010, secondary production has been increasing since the 1980's, with a level of $35 \%$ of total European supply in 2012. However, $51 \%$ of European Al supply is still covered by imports [8]. For countries without primary production (e.g. Austria), these trends could be even more pronounced. After the closedown of primary production in 1992, secondary production nearly sextupled between 1992 and 2012. The share of imports in total scrap inputs (excl. dross and internal scrap) of Austrian smelters is at a level of nearly $80 \%$. This highlights that even though $\mathrm{Al}$ is not a critical material in terms of global availability, continuous availability is crucial for maintaining the smelter industry and for the prosperous development of the economically important downstream industries. Hence, an evaluation of the possibilities and limits of increased recycling is important in understanding the potential for the domestic supply of secondary raw materials. This is illustrated for Austria by addressing the question of how future availability of national scrap resources could contribute to satisfying national $\mathrm{Al}$ demand. Therefore, a dynamic material flow model (dMFM) of anthropogenic $\mathrm{Al}$ stocks and flows [9] is extended to predict (potential) future $\mathrm{Al}$ recycling potentials. Building on the historical model, which delivers a timely discretized pattern of the current in-use stocks, a forecast of old scrap flows as well as in-use stock until 2050 is performed based on scenarios about future consumption trends and stock developments for various in-use sectors. By analysing the future trends in potential old scrap generation and in-use stock development, three major questions are tackled within this study: (1) how will the inuse stock and old scrap generation develop with respect to the major in-use sectors and different scenarios of future $\mathrm{Al}$ consumption? (2) What implications of future national selfsupply can be expected from predicted scrap amounts, both from a final consumption (= consumption at in-use) and an industry perspective? (3) To which extent are the results' uncertainties caused by parameter uncertainties in the historical model in contrast to uncertainties associated with scenario assumptions on future trends of $\mathrm{Al}$ production and consumption?

\section{Materials and Methods}

\section{Model Definition}

In a previous work [9], a dMFM of historical Al flows in Austria was developed. In this model, a plurality of data (e.g. historical production and trade data, material efficiencies, sector split ratios and average lifetimes) are considered in order to calculate annual in-use inputs, in-use stocks and old scrap generation with respect to the six major Al-use sectors:
Transport, Buildings and Infrastructure, Mechanical Engineering, Electrical Engineering, Consumer products, and Packaging. Through tracing the development of in-use stocks and old scrap flows, the total amount of $\mathrm{Al}$ in-use in 2012 is calculated (360 kg/cap.). Since most in-use sectors (except Packaging, where a stock is only built up for reusable packaging material) exhibit long average lifetimes, ranging from 10 years (Consumer products) up to 40 years (Buildings and Infrastructure), existing in-use stocks will have a strong influence on future old scrap generation.

However, in order to forecast development of in-use stocks and old scrap generation, the future final consumption of $\mathrm{Al}$ has to be considered as well. Therefore, the existing model of historical Al flows (Fig. 1 (left)) is combined with forecasts on future final $\mathrm{Al}$ consumption, and a forecast model of $\mathrm{Al}$ stocks and flows until 2050 based thereon is developed (Fig. 1 (right)). Future inputs are calculated individually for each sector either using a stock-driven or an input-driven approach (cf. Table 1).

\section{Future Consumption Scenarios}

Based on the calculated in-use inputs and in-use stocks (in 2012) of the historical model, future trends are extrapolated. Therefore, a stock-driven method $[10,11]$ is used for the sectors Transport, Building and Infrastructure and Electrical Engineering. For the Transport sector the growth of population, the level of motorization and the average $\mathrm{Al}$ content of new vehicles represent the key parameters of the model. The prediction of the future demand of $\mathrm{Al}$ in buildings is based on forecast data of the Austrian Conference on Spatial Planning concerning the future development of in-use stocks in residential buildings [12]. Since forecast data on non-residential buildings (commercial and infrastructure buildings) are not available, the non-residential building stock is assumed to grow at the same rate as the residential sector. For the Electrical Eng. sector, the growth rates of in-use stock are calculated based on the network development plan of the Austrian transmission system [13]. In order to account for different intensities of Al use for each sector, a base scenario (Middle Scenario), a scenario of high Al intensity (High Scenario) and a scenario of low Al intensity (Low Scenario) are defined. Middle, High and Low scenarios for stock-driven sectors are calculated through variation of the average $\mathrm{Al}$ content in new cars for the Transport sector, through different $\mathrm{Al}$ intensities in $\mathrm{kg} / \mathrm{m}^{2}$ for the Buildings and Infrastructure sector and through variation of system expansion in the power grid network for the Electrical Eng. sector. A detailed description of calculations of in-use stock development in the Transport as well as the Buildings and Electrical Eng. sectors is given in the Online Resources (OR). 


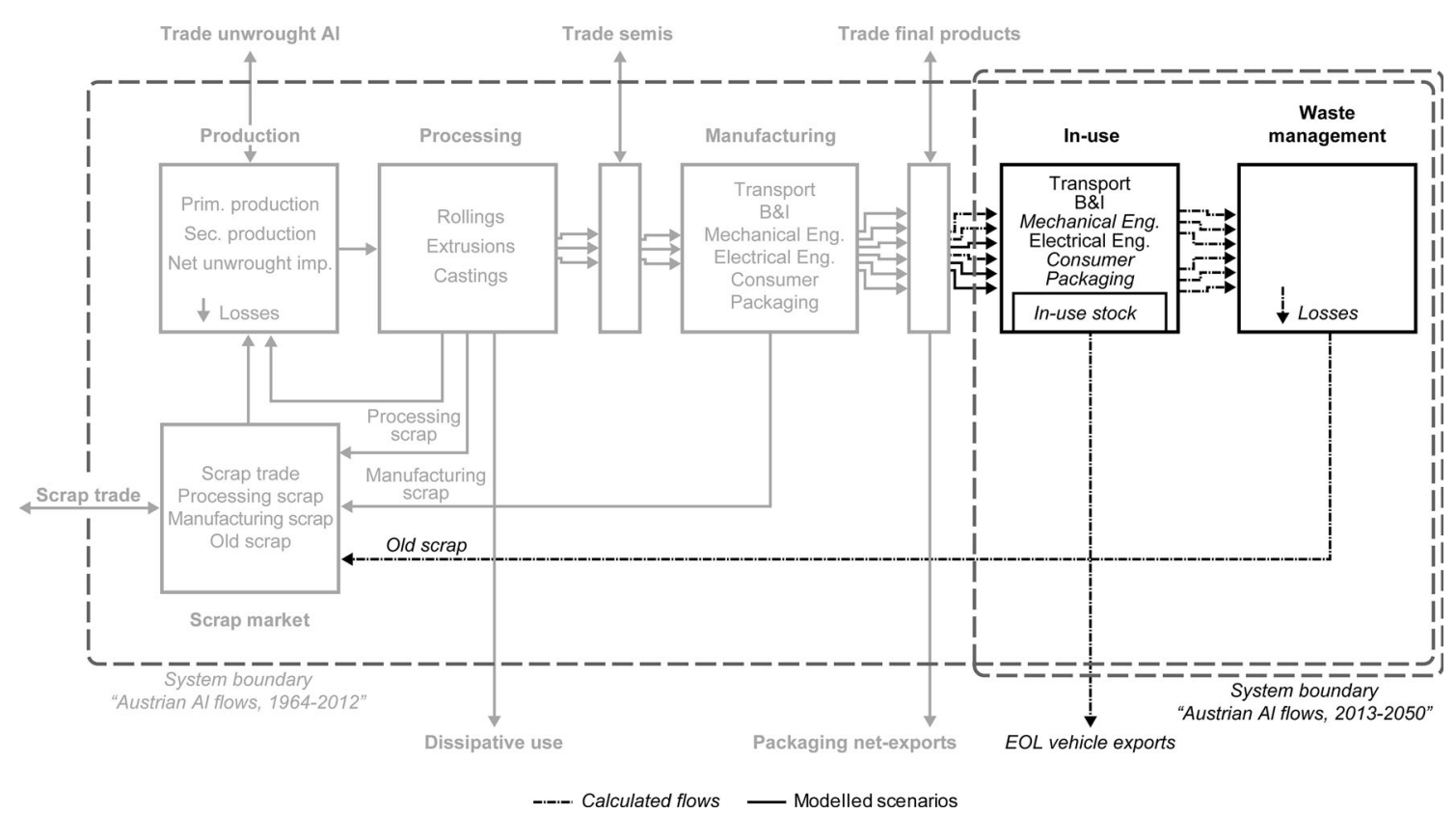

Fig. 1 System definition of the national Al flow system. Historical and future models are indicated through different system boundaries

Table 1 Scenarios of sectorspecific future Al final consumption differentiated by modelling method and $\mathrm{Al}$ intensity

\begin{tabular}{lllll}
\hline Sector & Method & \multicolumn{3}{l}{ CAGR and relative increases $^{\mathrm{b}}[2030,2050]$ in $\%$} \\
\cline { 3 - 5 } & & Low & Middle & High \\
\hline Transport & Stock-driven $^{\mathrm{a}}$ & $1.84[56,100]$ & $2.29[77,137]$ & $1.22[32,58]$ \\
Buildings and Infrastructure $^{\mathrm{a}}$ & Stock-driven $^{\mathrm{a}}$ & $1.34[41,66]$ & $1.53[49,78]$ & $2.31[82,138]$ \\
Mechanical Eng. & Input-driven & $1.29[25,63]$ & $1.86[38,101]$ & $2.32[50,139]$ \\
Electrical Eng. & Stock-driven $^{\mathrm{a}}$ & $1.44[72,72]$ & $1.85[87,101]$ & $2.25[103,133]$ \\
Consumer & Input-driven $^{\text {Packaging }}$ & $0.70[13,30]$ & $1.25[24,60]$ & $1.70[34,90]$ \\
& Input-driven & $0.49[9,21]$ & $1.39[27,69]$ & $2.06[46,117]$ \\
\hline
\end{tabular}

Annual increase of final Al demand expressed by compound annual growth rates (CAGR) and increase of final Al demand expressed as relative increase by 2030 and 2050 compared to the final Al demand of the Middle scenario in 2012

${ }^{a}$ CAGRs of final Al consumption have been recalculated from the stock modelling approach and are shown here for comparative purposes. Detailed data are used for model calculation (see Sect. 1 of the OR)

b Final Al demand of the middle scenario in 2013 is taken as the basis of comparison for each sector
For the remaining in-use sectors (Mechanical Eng., Consumer and Packaging), where available data are insufficient for a stock-driven approach, an input-driven approach is used. Thereby sector-specific forecasts on future $\mathrm{Al}$ final consumption in Europe are utilized [14]. The forecasts of $\mathrm{Al}$ final consumption in 2050 are therefore recalculated to annual growth rates given in Table 1 . The Middle scenario complies with the estimates provided by the EAA. For the High and Low scenario, the final consumption in 2050 is increased and decreased by $30 \%$, and the annual growth rates are adjusted accordingly. Regarding both approaches (stock-driven and input-driven), the applied High and Low scenarios are not intended to reflect extreme scenarios of $\mathrm{Al}$ use. They are intended to provide some variation of the base case (Middle scenario), especially in terms of uncertainty evaluation (cf. "Evaluation of Uncertainty" section). Since dMFM is more suitable for estimating long-term trends than estimating stock and flow values for certain years [9], the initial input values (year 2012) for the modelling of future flows are derived by a linear fit of historical inputs (see Chap. 2 of the OR). Years given in graphs and tables correspond to the particular calendar years.

\section{Defining Raw Material Self-supply}

A consistent definition and application of recycling indicators are a prerequisite for comparing efficiency of 
material use in different countries and systems $[15,16]$. According to the definition of the European Metals Association (Eurometaux), the End-of-Life recycling rate (EoL RR) is the main indicator for evaluating the efficiency of turning available old scrap into actual recycled old scrap [17]. EoL RR consists of the End-ofLife collection rate (EoL CR) and the End-of-Life processing rate (EoL PR). While the EoL RR provides information on the efficiency of the system regarding old scrap collection and processing, the recycled content is the share of old scrap in the material used for semis production [16], and thus is an indicator of raw material self-supply. Since unwrought Al trade flows could not be further distinguished as $\mathrm{Al}$ used for semis processing and $\mathrm{Al}$ used in production, in this study, the self-supply of $\mathrm{Al}$ is defined as the (potential) share of old scrap in national secondary $\mathrm{Al}$ production $\left(\mathrm{ss}_{\text {sec.prod }}\right)$ and national final consumption ( $\left.\mathrm{ss}_{\text {consumption }}\right)$, respectively [cf. to Eqs. (1) and (2)].

$\mathrm{ss}_{\text {sec.prod }}=\frac{\text { Total old scrap }}{\text { Sec.production }}$

$\mathrm{ss}_{\text {consumption }}=\frac{\text { Total old scrap }}{\text { Nat.consumption }}$,

where $\mathrm{ss}_{\text {consumption }}$ is calculated for the Middle scenario of final $\mathrm{Al}$ consumption; for the calculation of $\mathrm{ss}_{\text {sec.prod }}$, two different trends ( 2 and $4 \%$ CAGR) for national secondary $\mathrm{Al}$ production are assumed. In order to display the opportunities and limits of enhanced recycling (increased recycling is proposed in the EU Raw Materials Initiative), the old scrap collection rate in the model is stepwise increased (within 20 years) to a theoretical value of $90 \%$ for all sectors where current collection rates are below this value (recycling scenario $R_{\text {high }}$ ). Moreover, the potential for enhancing national $\mathrm{Al}$ recycling was investigated by assuming the termination of end-of-life vehicle exports (recycling scenario $R_{\max }$ ). In addition to collection losses, losses during processing [18] and melting [19, 20] are considered when calculating the rate of self-supply (Table 2).

\section{Evaluation of Uncertainty}

In the historical model, an uncertainty analysis regarding key parameters (sector split ratios, average lifetimes, and average $\mathrm{Al}$ content in final goods) has been conducted using Monte Carlo Simulations (MCS), in order to determine potential variability of final $\mathrm{Al}$ demand for every in-use sector. Thereby, the effect of parameter uncertainty on current stocks and flows of $\mathrm{Al}$ is considered. Detailed information on chosen mean values and parameter distributions is given in "Conclusions" section of the OR. Since inputs of the forecasting model do not further depend on sector split ratios and $\mathrm{Al}$ content in final goods produced in the past, since future stocks and flows have been based on the estimated stock and flows in 2012, the average lifetime is the only remaining uncertain parameter in the forecast model. Other information of limited certainty or assumptions (e.g. future $\mathrm{Al}$ content of passenger cars, number of cars) are accounted for via scenario analysis (Middle, High and Low scenario). These scenario uncertainties originate from the indeterminacy of future $\mathrm{Al}$ use. Average lifetimes and uncertainties of lifetime in the forecast model are fixed to the 2012 values. The average lifetimes are 16 years for Transport, 40 years for Building and Infrastructure, 17 years for Mechanical Eng., 30 years for Electrical Eng., 10 years for Consumer products and 5 years for reusable packaging material. The relative standard deviations are $20 \%$ for the lifetime estimates of each sector. In order to compare the effect of parameter uncertainties (originating from uncertain parameter values) with the effect of scenario uncertainty (originating from choice between Middle, High and Low scenarios) on total in-use stock and total old scrap generation, the empirical cumulative distribution functions (CDFs) are compared for the years 2010, 2030 and 2050. The relation between parameter and scenario uncertainty is evaluated by analysing the slope of the function curves (the flatter the curve, the larger is the range due to parameter uncertainties) and the distance between the resulting curves of the individual scenarios (the larger the distance, the higher is the effect of scenario assumptions on the results).
Table 2 Parameters CR, PR and melting yield for recycling scenarios $R_{\text {high }}$ and $R_{\text {max }}$

\begin{tabular}{lllll}
\hline & $\mathrm{CR}$ (current) $(\%)$ & $\mathrm{CR}\left(\right.$ scenario $R_{\text {high }}$ and $\left.R_{\max }\right)(\%)$ & PR (\%) & Melting yield (\%) \\
\hline Transport & 95 & 95 & $98^{\mathrm{a}}$ & $95^{\mathrm{a}}$ \\
Buildings and & 95 & 95 & & \\
$\quad$ Infrastructure & & & & \\
Mechanical Eng. & 80 & 90 & & \\
Electrical Eng. & 80 & 90 & & \\
Consumer & 50 & 90 & & \\
Packaging & 42 & 90 & & \\
Packaging (reuse) & 80 & 90 & & \\
\hline
\end{tabular}

${ }^{a}$ Same PR and melting yield is applied to all sectors 


\section{Results and Discussion}

\section{Future Development of In-Use Stocks and Old Scrap Generation}

The forecasts of total in-use stock and total old scrap generation for Austria are shown in Fig. 2a, b. Being at a level of 3.0 million tonnes (Mt) $(360 \mathrm{~kg} / \mathrm{cap}$.) at the end of 2012, total in-use stock increases to $3.9 \mathrm{Mt}$ (440 kg/cap.) at the end of 2030 and finally reaches $5 \mathrm{Mt}(530 \mathrm{~kg} / \mathrm{cap}$.) at the end of 2050. At the same time, annual old scrap generation increases from 125 thousand tonnes (kt) (14 kg/cap.) in 2012 to $210 \mathrm{kt}$ ( $24 \mathrm{~kg} / \mathrm{cap}$.) in 2030 and $290 \mathrm{kt}$ (31 kg/cap.) in 2050. Both in-use stock and old scrap generation are also shown for each in-use sector in Fig. 2c, d. The most pronounced increases in old scrap generation are expected for the Transport (3.1 times by

\section{Total in-use stock}
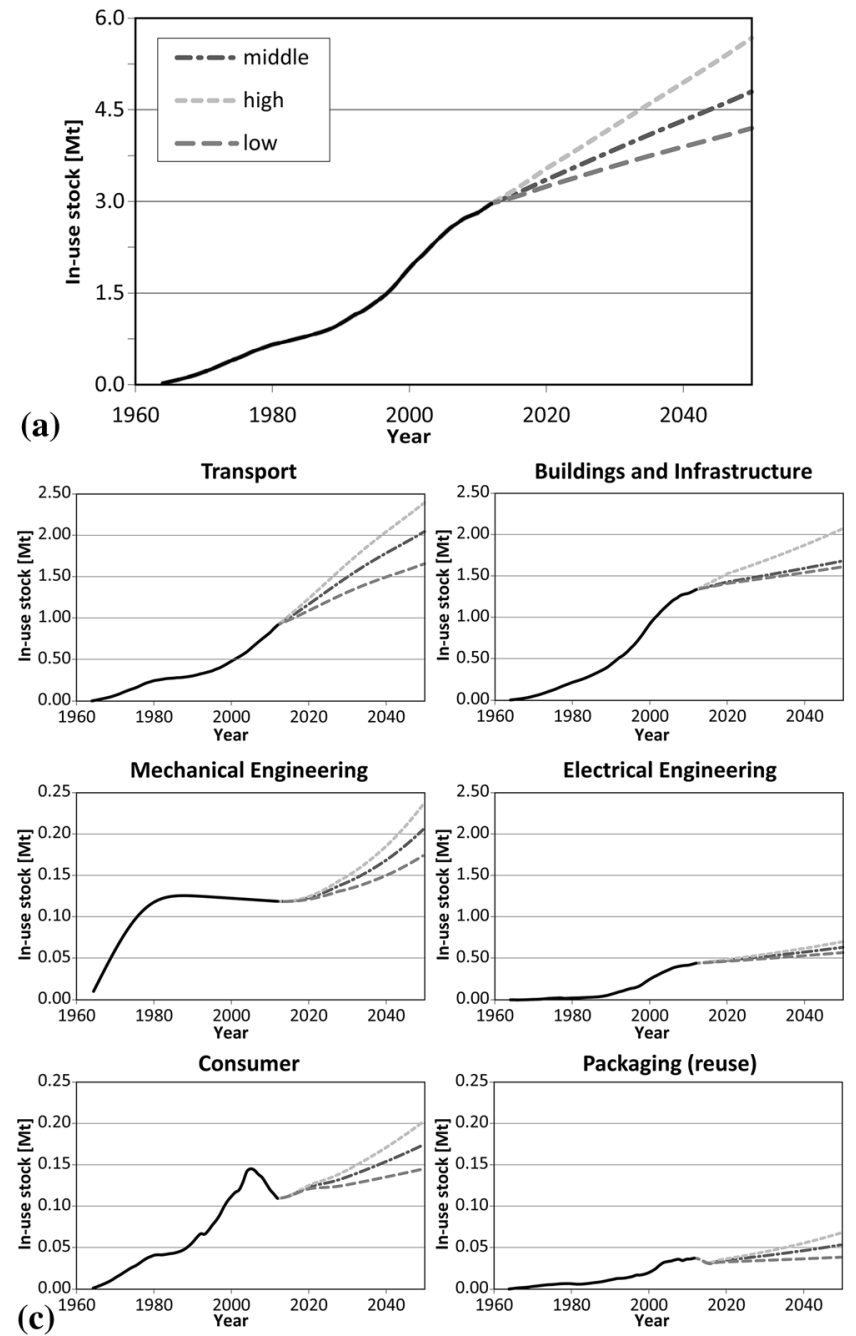

2050 in comparison to 2010) and the Building sectors (2.5 times by 2050). The Packaging sector's scrap generation is heavily dependent on the chosen consumption scenario due to the short residence time of packaging Al. For Electrical Eng., scrap generation increases by a factor 2.5 until 2050 . The plateau-shaped trend in Mechanical Eng. is mainly caused by the adjustment of input values (final $\mathrm{Al}$ demand) in the historical model (see SI). Therefore, it should be regarded as a poorly founded estimate; the predicted development of future scrap generation should thus be considered as an indicative trend only. Concerning the inuse stocks in single sectors, there is evidently no sign of saturation due to increasing final $\mathrm{Al}$ demand for the scenarios modelled, even though decreasing growth rates can be observed for some sectors (Transport, Buildings). The biggest in-use stock increase (relative to 2012) is observed for the Transport sector ( 2.3 times by 2050), followed by

(b)
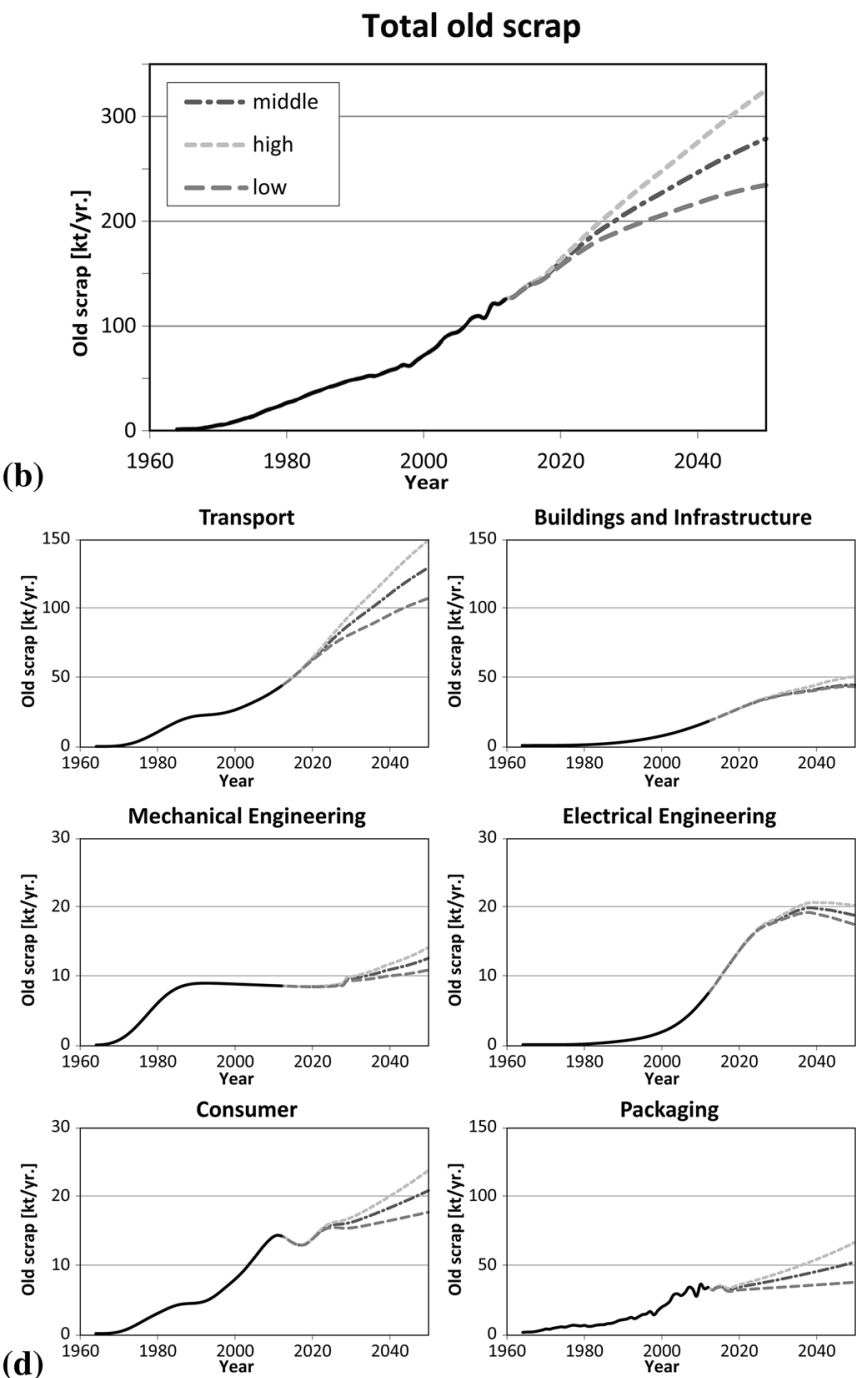

Fig. 2 In-use stocks and old scrap generation. Different scales are applied to the plots in sub-figure c and d, in order to highlight important and minor import sectors in terms of in-use stocks and old scrap generation 
reusable packaging material (1.8 times), Mechanical Eng. (1.7 times), Consumer (1.6 times), Electrical Eng. (1.4 times) and the Building sector (1.3 times). The Transport sector is by far the dominant driver of in-use stock growth, not just in relative but also in absolute terms. The growth rates of in-use stock of reusable packaging material, Mechanical Eng. and Consumer products are driven by the assumptions on increasing future consumption.

Future in-use stock saturation levels of $400 \mathrm{~kg} / \mathrm{cap}$. have been estimated for several European countries based on historical dMFM [21], which is in line with results in this study. However, the estimated saturation level on the European average of about $200 \mathrm{~kg} / \mathrm{cap}$. [22] is much lower than the anticipated developments of $\mathrm{Al}$ in-use stocks in Austria suggest. Since previous studies indicate that Austria has historically been a country of high $\mathrm{Al}$ consumption $[9,23]$, in-use stock levels above the European average seem plausible.

The increase in old scrap generation (2.3 times by 2050) is more pronounced than the increase in total in-use stock (1.7 times by 2050), which indicates, on the one hand, that an increasing amount of metal may be released from current (anthropogenic) in-use stocks and, on the other hand, that average growth in final consumption is expected to fall below historical values.

\section{Potential of Raw Material Self-supply}

Self-supply with Al old scrap in Austria is calculated with respect to the industrial Al demand (secondary Al production) and the final Al consumption. The latter is used to simulate the theoretical situation, where national Al demand (final goods) has to be covered by national secondary production, considering all foreign trade flows to be zero. Assuming a $2 \%$ CAGR for national secondary $\mathrm{Al}$ production, $\mathrm{ss}_{\text {sec.prod }}$ will remain quite constant at around $18 \%$, with a slightly decreasing trend after 2030 (cf. Fig. 3a). If secondary production grows at $4 \%$ CAGR, $\mathrm{ss}_{\text {sec.prod }}$ will continuously fall to a level below $10 \%$ by 2050. In view of the consumption, a $\mathrm{ss}_{\text {consumption }}$ around $40 \%$ of the consumption could be satisfied through domestic old scrap in the case of the Middle scenario (cf. Fig. 3b). Analysing the effect of enhanced recycling on self-supply with old scrap indicates that for the recycling scenario $R_{\text {high }}$, the national self-supply at in-use stage $\mathrm{ss}_{\text {consumption }}$ will increase to nearly $50 \%$. If exported "end of life" vehicles are additionally accounted for, national recycling $\mathrm{ss}_{\text {consumption }}$ may increase up to $74 \%$ by 2050 . However, from the production perspective, only a $3 \%$ increase of $\mathrm{ss}_{\text {sec.prod }}$ can be achieved by enhanced recycling given a $4 \%$ CAGR. If in addition vehicle exports are terminated, a $6 \%$ increase of $\mathrm{ss}_{\mathrm{sec} . \text { prod }}$ could be achieved.
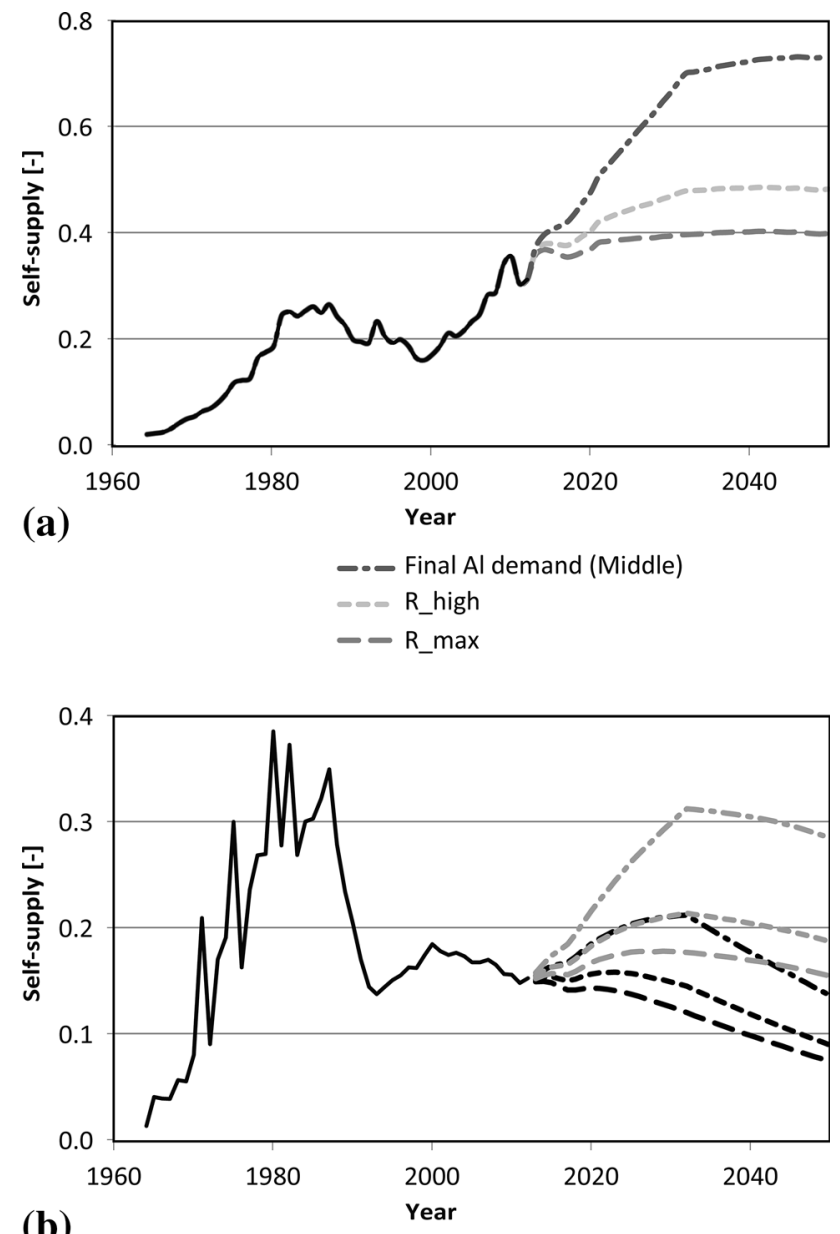

(b)

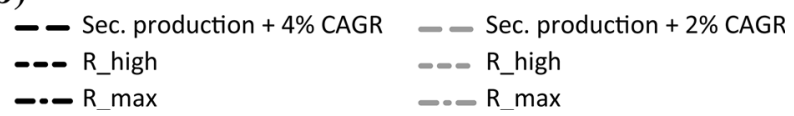

Fig. 3 a Self-supply regarding future old scrap generation and secondary production ( $\mathrm{ss}_{\text {sec.prod }}$ ) and $\mathbf{b}$ self-supply regarding future old scrap generation and in-use consumption ( $\left.\mathrm{ss}_{\text {consumption }}\right)$. Recycling scenarios $R_{\text {high }}$ and $R_{\max }$ are indicated in dashed lines

In the case of assuming a $2 \%$ CAGR for secondary production, the corresponding $\mathrm{ss}_{\text {sec.prod }}$ would reach around $30 \%$ by 2050 , highlighting the strong effect of the growth rate chosen on the potential for production of self-supply [16]. However, in analysing the potential effects on selfsupply through enhanced recycling measures, one has to keep in mind that not all vehicles exported nowadays are really scrap vehicles (e.g. used-car trade). Therefore, the effect of terminating vehicle exports on self-supply is probably overestimated in the present analysis (i.e. it is a partly unrealistic potential). Furthermore, processing scrap from the production of semi-finished products as well as manufacturing scrap is not considered in the calculation of self-supply. Processing scrap is mostly kept in a closed inhouse cycle and therefore not available on the scrap market, while subsequent manufacturing scrap is mostly 
recycled in an open loop on the market but also regarded as new scrap. By including manufacturing scrap, a $9 \%$ increase in industrial self-supply could be achieved currently. However, the effects of new scrap recycling in terms of resource and energy savings as well as environmental impacts certainly deviate from old scrap recycling, and therefore, new scrap should not be considered in terms of raw material substitution [18].

The trend of future self-supply regarding final Al consumption (Fig. 3b) indicates that complete self-supply by 2050 is not achievable given the growth rates assumed for Al consumption. Even in the best case scenario (high collection rates, no vehicle exports), self-supply could not surpass a level of $75 \%$. In order to contrast the forecasts of future $\mathrm{Al}$ consumption presented with the idea of decoupling [24], a scenario of constant per capita Al consumption is shown in Fig. 4. If per capita $\mathrm{Al}$ consumption remains constant at the level of 2012 (approx. $23 \mathrm{~kg} / \mathrm{cap}$.), the theoretical level of Al consumption self-supply could reach $83 \%$ by 2050 . In the case of constant per capita consumption, the amount of $\mathrm{Al}$ consumed increases by $11 \%$ compared to 2012 due to population growth. In order to arrive at a consumption self-supply level of $100 \%$ (i.e. final $\mathrm{Al}$ consumption $=\mathrm{Al}$ old scrap), Al per capita consumption would have to decrease by $30 \%$ until 2050 , assuming a linear decrease from current consumption levels. Such a $30 \%$ decrease of per capita consumption would correspond to a decrease of $23 \%$ in the total amount of Al consumed in Austria in the year 2050 compared to 2012. Trends in self-supply as well as total in-use stocks are shown in Fig. 4. Recycling (CR, PR) and production losses are not considered in the trends of self-supply (given in Fig. 4), thus resulting in a theoretical self-supply

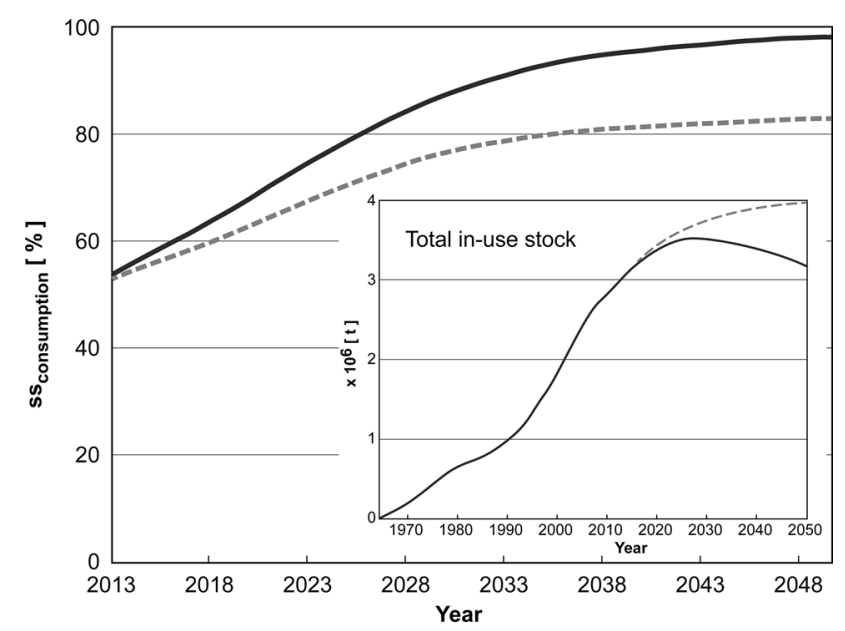

Fig. 4 Self-supply ( $\left.\mathrm{ss}_{\text {consumption }}\right)$ with constant per capita consumption (dashed line) and self-supply with a $30 \%$ decrease in per capita consumption (solid line) until 2050. Corresponding total in-use stock developments are shown to the right situation because $100 \%$ recovery of end-of-life $\mathrm{Al}$ is not possible in a real system due to dissipative losses during usage, considerably increasing recycling efforts in order to obtain high CR and PR and thermodynamic limitations in production.

\section{Parameter Versus Scenario Uncertainty}

The effects of parameter uncertainties (historical model) and scenario uncertainties (forecast model) on total in-use stock and total old scrap generation are shown in Fig. 5 for the years 2010, 2030 and 2050. Parameter uncertainty reflects the influence of the parameter values, chosen in the historical model, on current in-use stocks, which are of major importance to determine future old scrap generation. Scenario uncertainty reflects the indeterminacy of future final Al demand, which is approximated by choosing a range of scenarios (Low, Middle and High).

In 2010, the CDFs of the scenarios are practically identical for both in-use stock and old scrap generation as the estimated consumption scenarios are not relevant. From Fig. 5a, it becomes obvious that the curves for old scrap and total stock are oppositely skewed. Values of total old scrap generation are right-skewed (point of inflexion is in the lower half of the range), while in-use stock values are left-skewed (point of inflexion is in the upper half of the range). The data intervals containing $90 \%$ of the model results (between the 5 th and the 95 th percentile) are given in Table 3. In 2030, the influences of the consumption scenarios on in-use stock and scrap generation are indicated by the distance between the CDF curves of the individual scenarios. Regarding in-use stock, the Low and the Middle scenarios show very similar results, whereas the high consumption scenario exerts a more pronounced effect on the resulting in-use stock estimates. The uncertainty related to the average lifetimes in the forecast model and to the parameters of the historical model (sector split ratios, Al concentration in final goods and average lifetimes) causes nearly a doubling of the resulting uncertainty ranges (expressed via the $90 \%$ data intervals of the MCS results). In 2050, the distances between the Low and Middle scenario CDFs for in-use stock are practically the same as between the Middle and High scenarios. However, compared to 2030, the scenario choices have a higher influence in 2050 than the uncertainties of model parameters. For the total old scrap generation, similar patterns of parameter and scenario uncertainty are observed (cf. Fig. 5). Scenario-dependence increases over time, resulting in distinct displacement of the CDF curves in 2050. In contrast to scenario uncertainty, parameter uncertainty (width of the $90 \%$ data interval of a scenario CDF) decreases over time since after 2010 the only uncertain parameters remaining are the average sector-specific 


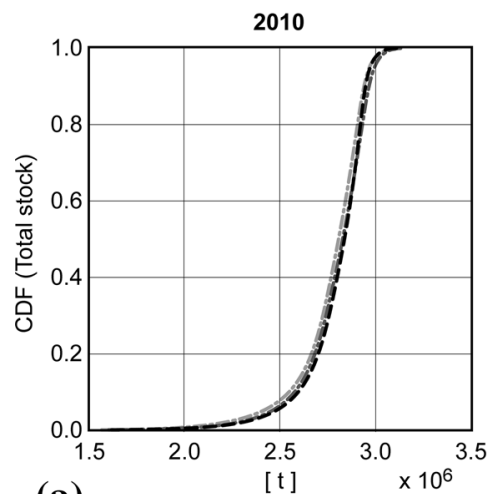

(a)

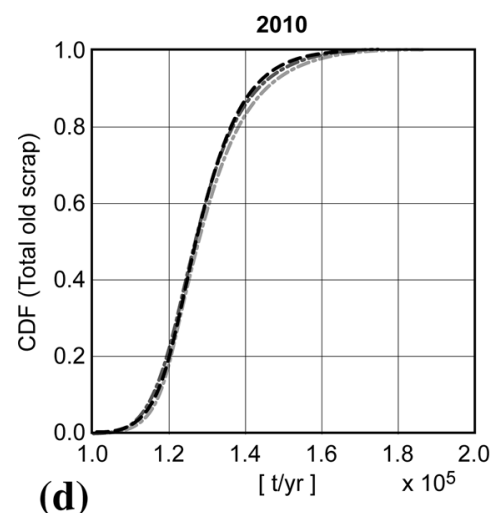

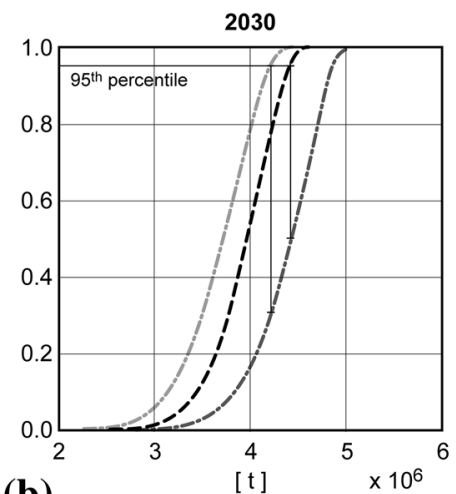

(b)

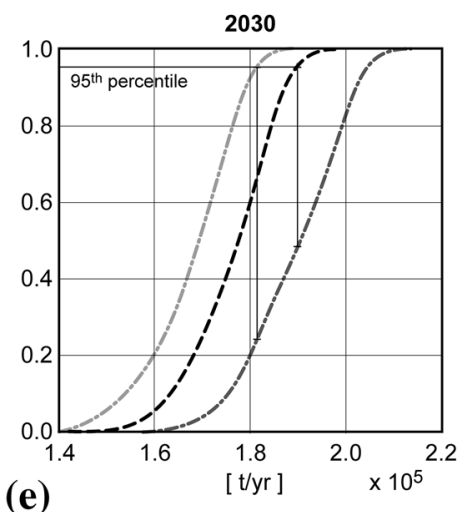

(e)

Middle

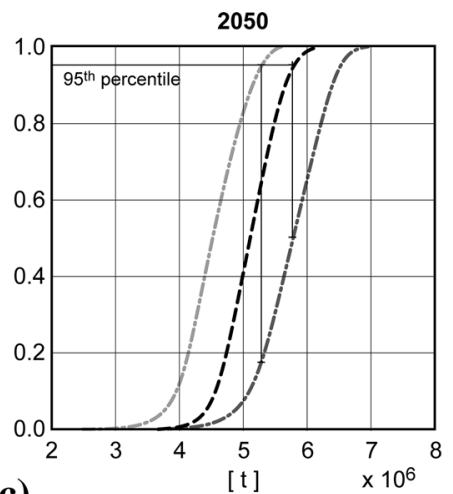

(c)

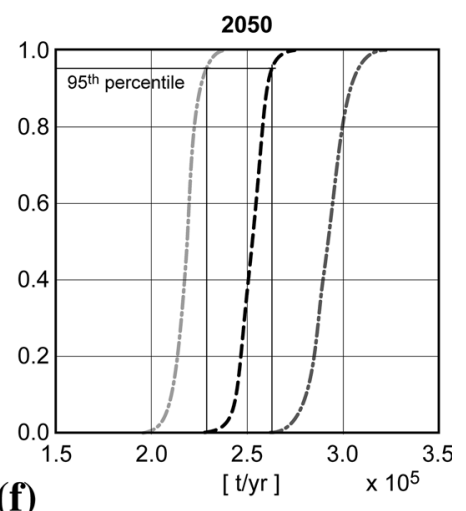

(f)

High

Fig. 5 CDF plots of total in-use stock and total old scrap generation for the years 2010, 2030 and 2050

Table 3 Intervals between the 5th percentile and the 95 th percentile (90\% data intervals) of the Monte Carlo simulation results for total in-use stock and old scrap generation

\begin{tabular}{|c|c|c|c|c|c|c|c|c|c|}
\hline & \multicolumn{3}{|l|}{2010} & \multicolumn{3}{|l|}{2030} & \multicolumn{3}{|l|}{2050} \\
\hline & Low & Middle & High & Low & Middle & High & Low & Middle & High \\
\hline Total in-use stock $\left[\mathrm{t} \times 10^{6}\right]$ & {$[2.4,3.0]$} & {$[2.4,3.0]$} & {$[2.5,3.0]$} & {$[3.0,4.2]$} & {$[3.2,4.5]$} & {$[3.7,4.9]$} & {$[3.8,5.3]$} & {$[4.4,5.9]$} & {$[5.0,6.6]$} \\
\hline Total old scrap $\left[\mathrm{t} \times 10^{5}\right]$ & {$[1.1,1.5]$} & {$[1.1,1.5]$} & {$[1.1,1.5]$} & {$[1.5,1.8]$} & {$[1.6,1.9]$} & {$[1.7,2.1]$} & {$[2.1,2.3]$} & {$[2.4,2.5]$} & {$[2.8,3.1]$} \\
\hline
\end{tabular}

lifetimes. Old scrap in 2050 therefore mainly depends on the choice of the consumption scenario and is hardly influenced by the uncertainty of model parameters.

The overlap of the Middle, High and Low consumption scenarios in 2030 and 2050 is indicated in Fig. 5b, c, e, f by vertical lines at the 95th percentiles of the Low and Middle scenarios. In the case of in-use stock, the 95th percentile of the Low scenario in 2030 (Fig. 5b) is higher than $75 \%$ of the simulated values of the Middle scenario and $30 \%$ above all values estimated for the High scenario. Thus, there is a $70 \%$ probability that the in-use stock resulting from the High scenario lies above the 95th percentile of the in-use stock resulting from the Low scenario in 2030. For 2050, the scenario-related differences increase and, consequently,
$80 \%$ of the High scenario results lie above the 95th percentile of the Low scenario results (Fig. 5c). The probability that the in-use stock of the High scenario is above the 95th percentile of the Middle scenario' results is around $50 \%$. With respect to total old scrap generation, the percentile comparisons indicate a stronger dependency of the results on the scenarios. For instance, only $65 \%$ of the Middle scenario results and $45 \%$ of the High scenario results are below the 95th percentile of the Low scenario in 2030 (Fig. 5e). In 2050, all of the results of the Middle scenario are above the 95th percentile of the Low scenario's old scrap generation (Fig. 5f). The same holds for the comparison between the Middle and High scenario, highlighting the dominating role of the scenario choices for these results. 


\section{Discussion of Scenario Trends}

According to the scenarios of future $\mathrm{Al}$ consumption analysed, the sectors Transport and Buildings will remain the key drivers of old scrap generation. Projected targets of increasing the $\mathrm{Al}$ content in cars, mainly driven by $\mathrm{Al}$ used for body-in-white and hang-on parts, will considerably increase the old scrap recycling potential from the transport sector [25]. Scrap generation from Buildings is dominated by the long average life times, which will make currently used $\mathrm{Al}$ available in future. In any case, concerning the Transport sector, it should be mentioned that the effect of a potential increase in electric cars at the expense of conventional cars is not considered in this study. An increase in the electric vehicle fleet would most likely induce a reduction of cast $\mathrm{Al}$ used in transport, whereas the use of wrought $\mathrm{Al}$ for structural parts would basically not be affected by the type of propulsion [26]. Cast $\mathrm{Al}$ content in future electric cars is expected around $50 \mathrm{~kg}$, compared to a quite constant $\mathrm{Al}$ content of around $100 \mathrm{~kg}$ in gasoline and diesel cars [26]. Considering the expected increase of wrought $\mathrm{Al}$ parts in cars, which will be the main driver of $\mathrm{Al}$ demand in the transport sector (electric and gasoline cars), an average Al content of 190, 270 and $320 \mathrm{~kg}$ per vehicle is estimated in this study (cf. Chapter 1 of the OR). Consequently, taking into account an increasing share of electric cars in the vehicle fleet would indicate a propensity to the Middle and Low scenarios of this study, where a lower average $\mathrm{Al}$ content per car is assumed. Drastic changes in terms of future electrical car penetration are not considered, because also the BLUE map scenario of the International Energy Agency expects that the share of conventional vehicles and vehicles with conventional components (hybrid, plug-in hybrid) in total light-duty vehicle sales will still be around $65 \%$ in 2040 [27], which indicates a continuing dominance of conventional, fuelbased technologies in vehicles. Nevertheless, increasing shares of electric cars might result in lower $\mathrm{Al}$ intensities and consequently in lower $\mathrm{Al}$ inputs to the Transport sector, than considered in the present analysis. However, it should also be noted that $\mathrm{Al}$ use is in competition with other light-weight materials [28]. Furthermore, there is no certainty that the same trend of increasing $\mathrm{Al}$ content also applies to other vehicle categories (e.g. commercial vehicles, motorbikes etc.), which is assumed in the present study. Considering the above-mentioned aspects influencing future $\mathrm{Al}$ use in cars, the scenario assumptions cover a plausible range of potential $\mathrm{Al}$ usage in cars without taking into account potential extreme developments in the Transport sector.

Similar assumptions have been made for the Building sector, where the calculated stock growth rate of residential buildings is also applied to buildings in the fields of commerce and infrastructure. Due to the currently higher $\mathrm{Al}$ intensity in commercial buildings, this assumption may lead to an underestimation of future stocks, but data on commercial buildings are not available for the case of Austria.

Comparing current secondary production to current final $\mathrm{Al}$ demand shows that final $\mathrm{Al}$ demand is currently in the magnitude of $50 \%$ of secondary production. If future secondary production grows at $4 \%$ CAGR and final $\mathrm{Al}$ demand at a level of 1-2\% CAGR, final $\mathrm{Al}$ demand will be only $20 \%$ of secondary production in 2050 . This clearly indicates that future growth of secondary production will be mainly driven by the export of products.

Based on increasing $\mathrm{Al}$ consumption in all in-use sectors, no saturation is observed for the in-use stocks in the model. Therefore, the present analysis provides some indication that saturation will not occur before 2050 in highly developed European economies, such as Austria. This is an important finding as the time required to reach a theoretical saturation level is a crucial assumption in stockdriven approaches to material flow modelling [21, 22].

\section{Conclusions}

As far as the raw material initiatives of the EU are concerned, it should be noted that self-supply from old scrap in Austrian secondary $\mathrm{Al}$ production will most likely not exceed $30 \%$, and even $30 \%$ would require quite restrictive measures limiting exports of end-of-life products (e.g. cars) in combination with increased $\mathrm{CR}$ in national recycling, as well as growth in national secondary production at a very moderate level of $2 \%$ CAGR. Assuming a $2 \%$ CAGR industry and increased national recycling efforts (without limits on exports of Al containing end-of-life products), a future self-supply between 15 and $20 \%$ may be achieved. In relation to the $\mathrm{Al}$ demand required to satisfy the domestic final consumption, self-supply increases over time with a theoretical maximal self-supply limit of around $70 \%$ for the given consumption scenarios. Comparing the different trends of self-supply at the level of industrial demand and at the level of final consumption, it turns out that a more differentiated view on limits and goals of managing secondary resources is necessary. If industry objectives on annual growth are achieved, enhanced recycling exhibits quite limited power for increasing self-supply without major export restrictions. At the level of final consumption, however, increasing levels of self-supply could be expected in the future in parallel with the decelerated growth of $\mathrm{Al}$ in-use stocks. Nevertheless, a theoretical Al self-supply of $100 \%$ by 2050 (losses not considered) could only be achieved through a $30 \%$ decrease of per capita $\mathrm{Al}$ consumption. Thus, a self- 
sustaining supply to satisfy final $\mathrm{Al}$ demand based on domestically available secondary raw materials could only be reached through a decrease in consumption, which seems rather unlikely given historic developments. Uncertainty analyses indicate that the assumed trends in future final $\mathrm{Al}$ demand as well as future trends in secondary production (scenarios) have a stronger effect on the potential self-supply than model parameter uncertainties (life time of $\mathrm{Al}$ containing products).

Finally, it needs to be emphasized that an increasing self-supply via old scrap may result in unsuitable alloy compositions for remelting, which was not considered in the present study. Very specific and well-defined alloys are necessary in order to ensure the requirements concerning product quality. A mix of old scraps from different applications could therefore lead to undesirable levels of certain alloy elements present in the scrap, which would put a limit on the maximum amount of old scrap to be used in secondary production. However, new technologies, such as sensor-based sorting, hold some promise for at least reducing this limitation in old scrap recycling. Because lifetimes for certain in-use sectors are long, variation of alloy types used over time could also pose a challenge to high levels of self-supply. Therefore, the investigation of future $\mathrm{Al}$ scrap qualities based on the $\mathrm{Al}$ alloys used in various application sectors can shed further light on the potential for $\mathrm{Al}$ recycling and secondary raw material use, warranting future research efforts.

Acknowledgments The work presented is part of a large-scale Research Initiative on Anthropogenic Resources (Christian Doppler Laboratory for Anthropogenic Resources). The financial support for this research initiative offered by the Federal Ministry of Science, Research and Economy and the National Foundation for Research, Technology and Development is gratefully acknowledged. Industry partners co-financing the Research Center on Anthropogenic Resources are Altstoff Recycling Austria AG (ARA), Borealis group, voestalpine AG, Wien Energie GmbH, Wiener Kommunal-Umweltschutzprojektgesellschaft $\mathrm{GmbH}$, and Wiener Linien GmbH \& Co KG.

\section{References}

1. European Commission (2014) Growth industry. http://ec.europa. eu/growth/industry/index_en.htm. Accessed 24 April 2015

2. European Commission (2014) For a European industrial renaissance. Brussels

3. European Commission (2008) The raw materials initiativemeeting our critical needs for growth and jobs in Europe. European Commission, Brussels

4. European Commission (2014) On the implementation of the raw materials initiative. European Commission, Brussels

5. Commission European (2011) Tackling the challenges in commodity markets and raw materials. European Commission, Brussels

6. Commission European (2014) Report on critical raw materials for the EU. European Commission, Brussels
7. van der Voet E, van Oers L, Huele R (2014) TNO report-topical paper 10: assessment of historical resource efficiency improvements in the aluminium industry Institute of Environmental Sciences CML. Leiden University, Delft

8. European Aluminium Association (2015) EU primary aluminium import dependency. http://www.alueurope.eu/production-eu-pri mary-aluminium-supply/. Accessed 27 April 2015

9. Buchner H, Laner D, Rechberger H, Fellner J (2015) Dynamic material flow modelling: an effort to calibrate and validate aluminium stocks and flows in Austria. Environ Sci Technol 49:8

10. Müller DB (2006) Stock dynamics for forecasting material flows - case study for housing in The Netherlands. Ecol Econ 59:142-156. doi:10.1016/j.ecolecon.2005.09.025

11. Hatayama H, Daigo I, Matsuno Y, Adachi Y (2010) Outlook of the world steel cycle based on the stock and flow dynamics. Environ Sci Technol 44:6457-6463. doi:10.1021/es100044n

12. Hanika A, Bauer E, Fassmann H, Lebhart G, Marik S, Münz R (2005) ÖROK-Prognosen 2001-2031/Teil 2: Haushalte und Wohnungsbedarf nach Regionen und Bez. Österreichs. Österreichische Raumordnungskonferenz (ÖROK), Wien

13. APG (2014) Netzentwicklungsplan 2013. Austrian Power Grid AG, Vienna

14. EAA (2012) An aluminium 2050 roadmap to a low-carbon Europe-lightening the load. European Aluminium Association, Brussels

15. Chen W (2013) Recycling rates of aluminium in the United States. J Ind Ecol 17:12

16. Rombach G (2013) Raw material supply by aluminium recycling-efficiency evaluation and long-term availability. Acta Mater 61:1012-1020. doi:10.1016/j.actamat.2012.08.064

17. Eurometaux (2012) Recycling rates for metals. European Association of Metals, Brussels

18. Reck BK, Graedel TE (2012) Challenges in metal recycling. Science 337:690-695. doi:10.1126/science.1217501

19. Sevigné-Itoiz E, Gasol CM, Rieradevall J, Gabarrell X (2014) Environmental consequences of recycling aluminum old scrap in a global market. Resour Conserv Recycl 89:94-103. doi:10.1016/ j.resconrec.2014.05.002

20. Cullen JM, Allwood JM (2013) Mapping the global flow of aluminum: from liquid aluminum to end-use goods. Environ Sci Technol 47:3057-3064. doi:10.1021/es304256s

21. Liu G, Bangs CE, Muller DB (2013) Stock dynamics and emission pathways of the global aluminium cycle. Nat Clim Change 3:338-342. http://www.nature.com/nclimate/journal/v3/n4/abs/ nclimate1698.html\#supplementary-information

22. Hatayama H (2009) Assessment of the recycling potential of aluminium in Japan, the United States, Europe and China. Mater Trans 50:7

23. Liu G, Müller DB (2013) Centennial evolution of aluminum inuse stocks on our aluminized planet. Environ Sci Technol 47:4882-4888. doi:10.1021/es305108p

24. von Weizsäcker EU, de Larderel J, Hargroves K, Hudson C, Smith M, Rodrigues M (2014) Decoupling 2: technologies, opportunities and policy options. A Report of the Working Group on Decoupling to the International Resource Panel. United Nations Environment Programme

25. EAA (2012) Aluminium in cars-unlocking the light-weighting potential. EAA, European Aluminium Association, Brussels

26. Modaresi R, Müller DB (2012) The role of automobiles for the future of aluminum recycling. Environ Sci Technol 46:8587-8594. doi:10.1021/es300648w

27. IEA (2010) Electric and plug-in hybrid vehicle roadmap. Int Energy Agency, Paris

28. Ghassemieh E (2011) Materials in automotive application, state of the art and prospects. InTech Open Access Publisher 